\title{
Psychological Predictors of Anxious Responses to the COVID-19 Pandemic: Evidence from Pakistan
}

\author{
Muhammad Waqas ${ }^{1}$, Alishba Hania ${ }^{\otimes}$, and Li Hongbo $^{1}$ \\ ${ }^{1}$ School of Management, Jiangsu University, Zhenjiang, China \\ ${ }^{2}$ Department of Psychology, Institute of Southern Punjab, Multan, Pakistan
}

Objective COVID-19 epidemic can be associated with a variety of anxious responses and safety behaviors. The present research explored the psychological implications associated with COVID-19 during the outbreak in 2020 to date. Pakistani media has given particular attention to this outbreak in the region.

Methods Three hundred and forty-seven undergraduate university students from Pakistan completed a battery of questionnaires focusing fear of COVID-19, associated safety behaviors, factual knowledge of COVID-19, and other psychological pointers hypothesized to be as predictors of anxious responses to COVID-19 threat and associated safety behaviors.

Results The sample appeared to be fearful of COVID-19 and this fear was related to disgust sensitivity, anxiety sensitivity-related physical concerns, body vigilance, contamination cognitions, and general distress. Results suggested that the tendency of overestimating the severity of contamination and anxiety sensitivity towards physical concerns are significant predictors of COVID-19 related fear and consequent safety behaviors.

Conclusion It is suggested that people with a greater concern of contamination are likely to respond fearfully to COVID-19 and that people with higher fear of COVID-19 are likely to feel contamination concerns.

Psychiatry Investig 2020;17(11):1096-1104

Key Words Corona virus, Pandemic, Health anxiety, Behavioral problem, Pakistan.

\section{INTRODUCTION}

World Health Organization declared coronavirus as a Pandemic in 2019. ${ }^{1}$ Since then the disease outbreak has been publicized leading to mass hysteria and health anxiety even for the medically healthy individuals. ${ }^{2}$ Currently, there is no literature on the psychological impacts of the COVID-19 pandemic on the general population of Pakistan. This is particularly relevant to the uncertainty associated with the unprecedented epidemic of such unparalleled magnitude. So far, the research related to COVID-19 has focused on the identification of epidemiological or the clinical characteristics of infected individuals, ${ }^{3,4}$ genomic characterization, and the challenges to global health governance. ${ }^{5,6}$

Though a limited body of research is found on the topic of

Received: May 9, 2020 Revised: June 30, 2020

Accepted: September 20, 2020

$\triangle$ Correspondence: Alishba Hania, $\mathrm{PhD}$

Department of Psychology, Institute of Southern Punjab, Multan 66000, Pakistan Tel: +923414486350, E-mail: alishba_hania92@hotmail.com

(a) This is an Open Access article distributed under the terms of the Creative Commons Attribution Non-Commercial License (https://creativecommons.org/licenses/by$\mathrm{nc} / 4.0$ ) which permits unrestricted non-commercial use, distribution, and reproduction in any medium, provided the original work is properly cited. anxiety among students and youngsters as a response to pandemic illnesses like Ebola, ${ }^{7}$ avian flu, ${ }^{8} \mathrm{H} 1 \mathrm{~N} 1,{ }^{9}$ and SARS.${ }^{10}$ However, there is no research considering the psychological impact of COVID-19 on the general population of Pakistan. The present study is therefore designed to represent the psychological impact of COVID-19 on the general population in the initial phase of the outbreak. The research aims to notify the prevalence of anxious responses and safety behaviors contributing to the fear of COVID-19. It is hoped that the research will assist government agencies and the healthcare professionals in designing preventative measures and safeguarding the psychological health of the Pakistani community in the face of the COVID-19 outbreak in Pakistan.

According to the notions, health anxiety is collectively defined as compulsive inappropriate and extreme thoughts about the status of one's health compared to the actual state of his health. ${ }^{11}$ Health anxiety is commonly dealt through behaviors that work in reducing the distress for a short time, ${ }^{12}$ like a frequent visit to clinics or hospitals, undue researching of symptoms through online sites, or continuously asking for reassurance from loved ones. However, in the long term, these behaviors are known to further enhance or maintain anxiety. ${ }^{13}$ Health 
anxiety interchangeably quoted as Illness anxiety is although known to be a diagnostic unit itself, it may still be seen in other psychological illnesses like somatic symptom disorder, obsessive-compulsive disorder, and other anxiety disorders. ${ }^{14}$ Further, it was stated that health anxiety with clinical severity along with linked safety behaviors can produce significant functional abnormality and distress. It is an established phenomenon that cases of health anxiety are high when the disease gets mass media coverage, for example when the Ebola outbreak was observed in late 2014.

World Health Organization declared confirmed cases across the globe as 200,000 patients with 8,000 confirmed death cases across 160 countries. ${ }^{1}$ Initially, the disease was originated and reported from Wuhan, China, after that in Europe, Italy was hit, and the immensely affected the country. ${ }^{15}$ The spread of the virus is dangerously rapid such that after two weeks of the first case, 1,000 patients were diagnosed. Another week passed by and the number of patients reached 46,000 and until March 2020 , the number of patients was 30,000, and the death count was $2,500 .{ }^{16}$ Lombardy is so far known to be the most affected region in the world, which forced the local institutes to reset the complete health care system and nationwide lockdown in Italy. ${ }^{17}$ Afterward, Spain declared the state of emergency on 14th March 2020 and announced special health care measures to be taken by the public. ${ }^{18}$

COVID-19 is known to have spread from China to 26 more countries throughout the globe. World Health Organization states that COVID-19 does not appear to be as deadly as other coronaviruses like MERS and SARS. However, COVID-19 has caused more demises (1871) than SARS and MERS (1632) both despite the notion of being less deadly. ${ }^{19}$ Mowbray and Beijing, ${ }^{20}$ states that coronavirus is more digital than viral as information being shared by social media, government, and health agencies are certainly reaching a record level in human history. For the moment death count is being closely monitored and stories of self or forced quarantine are being shared everywhere. Consequently, the risk of health appears to be rather scary and uncontrollable and eventually fuels the epidemic of fear. Gigerenzer, ${ }^{21}$ unbalanced, and unfiltered information often blurs the sound decision about health.

Research has significant empirical support that among the medically sound people, mass hysteria, and health anxiety is led by publicizing of disease outbreak. ${ }^{10}$ Anecdotally, in the clinics and hospitals of Pakistan, it has been seen that number of patients with presentations of OCD or IAD stated concerns for having COVID-19. ${ }^{22}$ It is vital to understand the psychological factors accompanied by health anxiety as a response to the threat of a disease because it can facilitate the treatment plans and preventative strategies for health anxiety. ${ }^{23}$ Heightened anxiety levels can also accompany safety behaviors (like avoidance, overutilization of health resources, or excessive washing) that are done to lessen the possibility of illness. Consequently, functional impairment and distress accompanies these safety behaviors and disturbs the natural homeostasis. ${ }^{24}$ Hence, this study was designed to explore the psychological variables associated with anxious responses associated with the threat of COVID-19. Variety of constructs that might predict such anxious responses were considered under the light of limited body of research addressing anxious responses among common men residing in the areas under the threat of pandemic illnesses, such as H1N1, ${ }^{9}$ avian flu, ${ }^{8}$ SARS10 and Ebola. ${ }^{7}$

One of the probable predictors for fear of COVID-19 and associated safety behaviors could be general stress like anxiousness or depressive symptoms. According to previously established notions, general stress along with anxiousness and depressive symptoms are strong predictors of physical health deterioration ${ }^{25,26}$ and negative interpretative biases (like catastrophizing) that further enhance anxiety about health and other illnesses. ${ }^{27}$ The second predictor is proposed as dysfunctional beliefs particularly those related to contamination because COVID-19 is known to be transmitted through bodily fluids. Moreover, the fear of COVID-19 could be the overestimation of the severity of contamination during this global outbreak. The third predictor is proposed as a propensity to experience disgust against the fear of COVID-19. ${ }^{28,29}$ Heightened response to disgust is potentially important as a predictor of not just contamination aversion but specifically for fear of COVID-19.

Body vigilance is another predictor against the fear of COVID-19, it is defined as a tendency to carefully monitoring bodily sensations. ${ }^{30}$ Olatunji et al. ${ }^{31}$ suggest that chance to notice an otherwise benign condition and translating them as catastrophic is high among people who frequently and intensively scan their physical appearance or sensations. It was also found in their research that body vigilance is a significant correlate of health anxiety between clinical and non-clinical adults. Furthermore, anxiety sensitivity is a predictor to fear of COVID-19 and safety behaviors because people with high sensitivity to anxiety are known to possess the tendency to misread benign sensations of arousal as a danger alert. ${ }^{32}$ Specifically, the degree to which a person concentrates on his body sensations like nausea, etc, is related to the urges against a variety of safety behaviors. Alternatively, according to the propositions of American psychological association about the safety behaviors of people against an epidemic, people who possess a greater understanding of the disease are less likely to feel anxious as a response to domestic outbreak. ${ }^{33}$

As discussed above, the extent of literature provides suggestions towards the factors that could predict COVID-19 related fear and consequent behaviors. Hence, it is hypothesized that a higher level of general distress, disgust sensitivity, body vig- 
ilance, contamination cognition, and anxiety sensitivity along with the decreased level of factual knowledge about an epidemic can predict COVID-19 related fear and safety behaviors.

\section{METHODS}

\section{Participants}

Three hundred and ninety undergraduate university students from Pakistan participated in the present research. The research was advertised for data collection through the online participant pool monitored by the Department of Psychology, Institute of Southern Punjab. At first, data were screened, and 40 participants were excluded based on incomplete questionnaires, bringing the final sample size to 350 respondents. Mostly female representation was shown in the data $(\mathrm{n}=194 ; 56 \%)$. The mean age noticed from the sample was 18.43 -year-old (ranged 18-21 years).

\section{Procedure}

Undergraduate students from central public universities of Pakistan were contacted and consents were taken to participate in present survey research. The duration for data collection was between March 4th, 2020 to April 6th, 2020. Respondents were asked to complete the questionnaires including a demographic Proforma. Following the instructions from Meade and $\mathrm{Craig}^{34}$ the validity of responses was assured by quoting four questions with instructions, "Answer Always True for this question." The study was conducted after sorting approval from the university's review board and consents were taken from respondents after they were informed about the purpose of the study (No.ISP/ADR/N/5784).

\section{Questionnaires}

\section{COVID-19 Fear Inventory (CFI)}

CFI was specifically constructed for present research and constituted of 9 items. The purpose of developing this inventory was to analyze the fear associated with COVID-19. Psychometric properties were analyzed and presented in the following section of preliminary analyses. Items were rated on a 5-point likert scale, options stating 1 (not at all) to 5 (very much). The questionnaire was inspired by previously constructed questionnaire for $\mathrm{H} 1 \mathrm{~N} 1 .^{8} \mathrm{CFI}$ showed satisfactory internal consistency $(\alpha=0.88)$ for the present sample.

\section{COVID-19 Checklist for Safety Behaviors (CCSB)}

CCSB was developed to inquire about the safety behaviors associated with fear of COVID-19. The checklist constitutes of 9 items. This inquires about the safety behaviors intended to prevent contacting COVID-19, examples include "washing hands compulsively, continuously checking the internet for COVID-19 and avoiding people." This checklist was also inspired by a previously constructed questionnaire for H1N1. ${ }^{8}$ Respondents were asked to rate the extent to which they are engaging in activities while having concerns about COVID-19 on a 10 -point scale ( $0=$ none to 10 extreme amount). The checklist showed satisfactory internal consistency $(\alpha=0.89)$ for current data.

\section{Depression Anxiety Stress Scales-21 (DASS-21) ${ }^{35}$}

Subjective distress over the last few weeks was assessed through three subscales of DASS-21 (Depression, Anxiety, and Stress). The scale constitutes of 42 items originally, but present research used the short form version comprised of 21 items by Lovibond and Lovibond. ${ }^{36}$ The respondents were asked to rate how each of these 21 statements is applied to them. The rating was done on a 4-point likert scale ranging from $0=$ rarely to $4=$ very much. The scale showed satisfactory reliability and construct validity for clinical and the non-clinical population in a previous study by Henry and Crawford. ${ }^{37}$ For the present research, the data responses showed $\alpha=0.94$.

\section{Contamination Cognitions Scale (CCS) ${ }^{38}$}

CCS is an inventory designed to assess the tendency of respondents to overestimate the chance of contamination from a variety of common objects like stairway railing etc. The items are rated on $0=$ not at all to $100=$ extremely. The scale was divided in terms of severity levels into two subscales of severity and likelihood with each subscale consisting of 13 items and a total of 26 items. For the current sample, the internal consistency of CCS-L and CCS-S was 0.95 and 0.96 respectively.

\section{Disgust Scale-Revised (DS-R) ${ }^{29}$}

The revised version of Haidt et al. ${ }^{39}$ of used to analyze the propensity of the sample to experience disgust across numerous domains. The objective view of respondents was taken in terms of multiple scenarios like if you see maggots on a piece of bread in an outdoor garbage pail, how disgusting do you find it on a scale of $0=$ strongly disagree to $4=$ strongly agree. Internal consistency was found satisfactory $(\alpha=0.87)$ and convergent validity was analyzed previously by Olatunji and Sawchuk. ${ }^{24}$

\section{Body Vigilance Scale (BVS) ${ }^{40}$}

The scale was designed to analyze the tendencies of respondents towards attending anxiety-related bodily sensations. The first three items of the scales are focused to analyze three dimensions focusing the attention, sensitivity towards change, and the duration devoted to monitoring body sensations on a scale 0 (not at all) to 10 (extremely). Fourth items separately inquired about fifteen bodily sensations and the extent to 
which attention is paid on each of them. These representations of bodily sensations are then averaged to get a single item's score. Previously the scale has shown satisfactory reliability ${ }^{24,30}$ and for the present research, the scale showed $(\alpha=0.94)$.

\section{Anxiety Sensitivity Index-3, Subscale for physical concerns $^{32}$}

The scale was adapted from the original version of Reise et al. ${ }^{41}$ It consists of 18 items that measured beliefs related to the dangerousness of anxious thoughts along with physical, cognitive, and social domains. The items were rated on 4-point rating scales ( $0=$ very little to $4=$ very much). Previously Taylor et al., ${ }^{32}$ showed satisfactory convergent validity, criterionrelated validity, and discriminant validity for Anxiety Sensitivity Index-3. For the current research, only physical concerns were analyzed because they were related to the aims of this research. The internal consistency of the scale was $\alpha=0.81$.

\section{COVID-19 Fast Quiz (CFQ) ${ }^{42}$}

CFQ is a ten-item yes or no based measure of knowledge about the COVID-19 and 2019 global outbreak. A high score indicated high knowledge about the virus and the outbreak. The quiz was originally shared in March 2020 by UK's Independent Fact-Checking Authority. ${ }^{42}$

\section{Data analysis and screening strategy}

Initially, for CFI and CCSB the item analysis was conducted to test psychometric properties, item-total correlation, and internal consistency. Afterward, to explore the relationship of constructs, CFI, and CCSB were correlated with other study variables. The researcher has used a linear regression model to determine the predictability of psychological variables (Depression, Anxiety, and Stress; Contamination Cognitions; Disgust sensitivity; Body vigilance; Sensitivity to anxiety and Knowledge of COVID-19) for COVID-19 fear and safety behaviors and to explore their univariate associations.

Among 350, two participants did not qualify for three distractor items and were excluded from further data analysis. Data were further screened for concordance with statistical assumptions. On the CCS-S item range, one case did not properly come within the acceptable range as possible range was 0 till 100, the case showed a score of 740, therefore it was excluded from final data. All values appeared to be free of significant skew i.e. less than 2 and the kurtosis less than 4 . Univariate outliers were not observed, however, two multivariate outliers were observed for whom Mahalanobis distances were beyond critical $\chi^{2} \mathrm{df}=8$ value of 26.12 . Outliers' status for multivariate outliers was driven by the infrequent combination of scores on BVS, CCS-L, CCS-S, and DASS for two participants. Such multivariate cases were excluded due to the chance of bias in regression estimation points and a sufficiently large sample. Distribution of scores for the remaining sample of 347 respondents was tested again and no significant skew, kurtosis, univariate or multivariate outlier indices were found.

\section{RESULTS}

\section{Descriptive data and statistics}

The following Table 1 suggest that although respondents were fearful on a high scale but were at least fearful on a moderate level. According to the data collected on safety behaviors employed by respondents in the result of COVID-19 fear, it is seen that respondents were performing a moderate level of COVID-19 related safety behaviors. The remaining measures showed scores ranged within a typical scale of the non-clinical population. In Table 1, it is also showed that respondents appeared to have a variable degree of knowledge regarding COVID-19 and its outbreak.

\section{Preliminary examination}

Following the outline of DeVellis, ${ }^{43}$ the COVID-19 Fear Inventory (CFI) was assessed for psychometric acceptability. For the measure of CFI, two items appeared to be falling below the acceptable level of 0.30 as suggested by Nunnally and Bernstein. ${ }^{44}$ Items number 6 and 8 were removed and it was seen that total scale reliability significantly improved. The final scale was based on 9 items and reliability was $\alpha=0.78$. The distribution of scores without any significant skew and kurtosis 1.36 and 1.39 respectively. Items that were removed from the scale, "If you were infected by COVID-19, to what extent are you concerned that you would die" and "How much information

Table 1. Descriptive explanation

\begin{tabular}{lcccccc}
\hline Questionnaire & $\mathrm{M}$ & $(\mathrm{SD})$ & Min & Max & Skew & Kurtosis \\
\hline CFI & 14.12 & $(5.45)$ & 9 & 30 & 1.35 & 1.38 \\
CCSB & 10.15 & $(10.63)$ & 0 & 53 & 1.63 & 2.45 \\
DASS-21 & 68.50 & $(20.78)$ & 43 & 120 & 1.01 & 0.42 \\
CCS-L & 33.94 & $(21.99)$ & 0.76 & 85.15 & 0.44 & -0.78 \\
CCS-S & 35.19 & $(21.56)$ & 0 & 100 & 0.76 & 0.05 \\
DS-R & 7.34 & $(0.56)$ & 6.78 & 9.48 & 0.55 & 0.06 \\
BVS & 19.65 & $(6.51)$ & 4.18 & 35.96 & 0.03 & -0.63 \\
ASI-3 physical & 3.34 & $(4.29)$ & 0 & 20 & 1.11 & 1.05 \\
CFQ & 3.79 & $(1.01)$ & 1 & 7 & 0.16 & -0.54 \\
\hline
\end{tabular}

CFI: COVID-19 Fear Inventory, CCSB: COVID-19 Checklist for Safety Behaviors, DASS-21: Depression Anxiety Stress Scales-21, CCS-L: Contamination Cognitions Scale-Likelihood average, CCS-S: Contamination Cognitions Scale-Severity average, DS-R: Disgust Scale-Revised average, BVS: Body Vigilance Scale, ASI-3 Physical: Anxiety Sensitivity Inventory-3 Physical Concerns Subscale, CFQ: COVID-19 Fast Quiz 
do you think you have about COVID-19." Similarly, DeVillis ${ }^{43}$ was followed to establish the COVID-19 Checklist for Safety Behaviors (CCSB) and its psychometric properties. For this measure, no items were removed, and all showed an acceptability level higher than 0.30 according to the suggestions of Nunnally and Bernstein. ${ }^{44}$ The final scale showed a reliability of $\alpha=0.88$. The distribution of scores was also without any significant skew and kurtosis (1.35 and 1.36 respectively) (Table 2 for item properties of COVID-19 Fear Inventory is as follows).

\section{Two-tailed zero order correlation}

The relationship between COVID-19 related fear, safety behaviors, and other variables was examined by a two-tailed zero-order correlation. The results in Table 3 suggest that CFQ is not significantly related to any of the study variables. However, other study variables showed a significantly positive correlation with each other.

\section{Regression analysis for predicting COVID-19 fear}

To explore the predicting capacity of psychological vari- ables towards COVID-19 fear, linear regression analysis was used (Table 4). Multicollinearity indices were satisfactory but suggested a lack of redundancy in the predictors of the model. The model suggests all tolerance values $\geq 0.57$ and $\mathrm{VIF} \leq 1.75$. The overall model accounts for $30 \%$ of the variance in CFI, F $(7,99)=5.10, \mathrm{p}<0.001$. Within the complete model, two predictors appeared to significantly or edict the fear of COVID-19 with $\mathrm{p} \leq 0.05$. Table 4 shows that the Contamination Cognitions Scale-Severity average accounted for $8 \%$ of the variability in CFI and the sensitivity to anxiety accounts for $4 \%$ of the variation in CFI. None of the other variables, DASS, DS-R, EFQ, CCS-L, or BVS independently predicted COVID-19 fear in the population from Pakistan in the current study (Table 4).

\section{Regression analysis to predict COVID-19 safety behaviors}

To explore the predicting capacity of psychological variables towards safety behaviors against COVID-19, the linear regression analysis was done (Table 5). Multicollinearity indices were satisfactory with tolerance value $\geq 0.57$ and all the VIF

Table 2. Item properties of COVID-19 Fear Inventory (CFI)

\begin{tabular}{|c|c|c|c|c|}
\hline & M & SD & $\begin{array}{l}\text { Item total } \\
\text { correlation }\end{array}$ & $\begin{array}{l}\alpha \text { if item } \\
\text { deleted }\end{array}$ \\
\hline 1. To what extent are you concerned about COVID-19? & 1.38 & 0.75 & 0.71 & 0.77 \\
\hline 2. To what extent do you believe that COVID-19 could become a "pandemic" in Pakistan? & 1.40 & 0.82 & 0.70 & 0.78 \\
\hline 3. How likely is it that you could become infected with COVID-19? & 1.37 & 0.85 & 0.77 & 0.76 \\
\hline 4. How likely is it that someone you know could become infected with COVID-19? & 1.22 & 0.57 & 0.69 & 0.78 \\
\hline 5. How quickly do you believe contamination from COVID-19 is spreading in the Pakistan? & 1.62 & 0.80 & 0.68 & 0.77 \\
\hline 6. To what extent has the threat of COVID-19 influenced your decisions to be around people? & 1.66 & 0.70 & 0.49 & 0.78 \\
\hline 7. To what extent has the threat of COVID-19 influenced your travel plans? & 1.22 & 0.89 & 0.70 & 0.79 \\
\hline $\begin{array}{l}\text { 8. To what extent has the threat of COVID-19 influenced you to use decontamination aids } \\
\text { (e.g., use hand sanitizer)? }\end{array}$ & 1.48 & 0.96 & 0.71 & 0.78 \\
\hline $\begin{array}{l}\text { 9. To what extent has the threat of COVID-19, influenced you to keep access to } \\
\text { decontamination aids (e.g., access to hand sanitizer)? }\end{array}$ & 1.88 & 0.93 & 0.77 & 0.77 \\
\hline
\end{tabular}

Table 3. Correlation between CFI, CCSB, DASS-21, CCS, DS-R, BVS, ASI-3, and CFQ

\begin{tabular}{|c|c|c|c|c|c|c|c|c|}
\hline & CFI & CCSB & DASS-21 & CCS-L & CCS-S & DS-R & BVS & ASI-3 \\
\hline CCSB & $0.60^{\ddagger}$ & -- & -- & -- & -- & -- & -- & -- \\
\hline DASS-21 & $0.21^{*}$ & $0.26^{\dagger}$ & -- & -- & -- & -- & -- & -- \\
\hline CCS-L & $0.33^{*}$ & $0.37^{\dagger}$ & 0.13 & -- & -- & -- & -- & -- \\
\hline CCS-S & $0.44^{\ddagger}$ & $0.56^{\ddagger}$ & 0.18 & $0.61^{\ddagger}$ & -- & -- & -- & -- \\
\hline DS-R & $0.36^{\dagger}$ & $0.48^{\ddagger}$ & 0.12 & $0.44^{\ddagger}$ & $0.34^{\ddagger}$ & -- & -- & -- \\
\hline BVS & $0.28^{\dagger}$ & $0.45^{\ddagger}$ & $0.47^{\ddagger}$ & $0.41^{\ddagger}$ & $0.22^{\ddagger}$ & $0.31^{\ddagger}$ & -- & -- \\
\hline ASI-3 physical & $0.37^{\ddagger}$ & $0.51^{\ddagger}$ & $0.45^{\ddagger}$ & $0.30^{*}$ & $0.28^{\dagger}$ & $0.28^{\dagger}$ & $0.47^{\ddagger}$ & -- \\
\hline CFQ & 0.03 & 0.05 & 0.11 & -0.05 & -0.05 & -0.05 & 0.04 & 0.07 \\
\hline
\end{tabular}

${ }^{*} \mathrm{p}<0.05,{ }^{\dagger} \mathrm{p}<0.01,{ }^{\ddagger} \mathrm{p}<0.001$. CFI: COVID-19 Fear Inventory, CCSB: COVID-19 Checklist for Safety Behaviors, DASS-21: Depression Anxiety Stress Scales-21, CCS-L: Contamination Cognitions Scale-Likelihood average, CCS-S: Contamination Cognitions Scale-Severity average, DSR: Disgust Scale-Revised average, BVS: Body Vigilance Scale, ASI-3 Physical: Anxiety Sensitivity Inventory-3 Physical Concerns Subscale, CFQ: COVID-19 Fast Quiz 
$\leq 1.75$. The regression model was overall suggesting $38.5 \%$ of the variance in CCSB scores, $\mathrm{F}(7,99), \mathrm{p}<0.001$.

The model suggests that the Contamination Cognitions Scale-Severity average and Disgust Scale-Revised average were the significant individual predictors for COVID-19 safety behaviors ( $\mathrm{p} \leq 0.05)$. Moreover, the concerns of people regarding contamination accounted for $8.7 \%$ of the variance in the model, and sensitivity to disgust accounted for $2.8 \%$ of the total variance in the model. None of the other study variables independently predicted the safety behaviors for the current sample ( $p$ values $\geq 0.060$ ) (Table 5).

\section{DISCUSSION}

This research intended to explore the psychological determinants of fear and anxious behavioral responses to the Corona Virus outbreak of 2019. It was hypothesized that among the selected respondents from our sample of university students, some of the predictors would be general psychological distress, disgust sensitivity, anxiety sensitivity, body vigilance, and the concerns for contamination. Moreover, factual knowledge about the COVID-19 outbreak was hypothesized to be a significant predictor for a decrease in COVID-19 related fear and safety behaviors. To meet the aims of this research, the researcher designed the measures for COVID-19 related fear inventory and an inventory for safety behaviors. The measures were reported to possess acceptable psychometric properties. Variables were tested for correlation among each other and it was found that contamination cognition, disgust sensitivity, body vigilance, anxiety sensitivity towards physical concerns, and general distress positively correlated with fear and safety behaviors associated with COVID-19. However, the hypothesis regarding the relationship between factual knowledge of COVID-19 and fear of disease was not significant. The model was tested as a simultaneous regression model and it suggested that overestimation in the severity of contamination significantly predicts the fear of COVID-19 and its associated safety behavior. Sensitivity to physical anxiety significantly determined fear of COVID-19 but only marginally predict COVID-19 related safety behaviors. Body vigilance was also marginally significant in predicting COVID-19 related safety behaviors. Generally, it can be stated that our results partially support our initial hypothesis.

An interesting exploration by this study is regarding the non-

Table 4. Linear regression analysis predicting COVID-19 fear

\begin{tabular}{lccccccc}
\hline \multicolumn{1}{c}{ Predictors } & $\mathrm{B}$ & $\mathrm{SEB}$ & $\mathrm{B}$ & $\mathrm{t}$ & $\mathrm{p}$ & Zero-order $\mathrm{r}$ & $\mathrm{sr}^{2}$ \\
\hline DASS-21 & -0.014 & 0.034 & -0.015 & -0.163 & 0.854 & 0.201 & $<0.001$ \\
CCS-L & -0.013 & 0.036 & -0.103 & -0.876 & 0.377 & 0.331 & 0.005 \\
CCS-S & 0.072 & 0.042 & 0.364 & 3.121 & 0.001 & 0.306 & 0.082 \\
DS-R & 0.862 & 0.592 & 0.137 & 1.201 & 0.247 & 0.286 & 0.087 \\
BVS & 0.085 & 0.051 & 0.146 & 1.346 & 0.183 & 0.266 & 0.014 \\
ASI-3 physical & 0.246 & 0.137 & 0.217 & 1.888 & 0.050 & 0.367 & 0.040 \\
CFQ & 0.159 & 0.267 & 0.049 & 0.555 & 0.550 & 0.043 & 0.002 \\
\hline
\end{tabular}

CFI: COVID-19 Fear Inventory, CCSB: COVID-19 Checklist for Safety Behaviors, DASS-21: Depression Anxiety Stress Scales-21, CCS-L: Contamination Cognitions Scale-Likelihood average, CCS-S: Contamination Cognitions Scale-Severity average, DS-R: Disgust Scale-Revised average, BVS: Body Vigilance Scale, ASI-3 Physical: Anxiety Sensitivity Inventory-3 Physical Concerns Subscale, CFQ: COVID-19 Fast Quiz, $\mathrm{sr}^{2}$ squared semi-partial correlation

Table 5. Linear regression analysis predicting COVID-19 safety behaviors

\begin{tabular}{lccccccc}
\hline \multicolumn{1}{c}{ Predictors } & $\mathrm{B}$ & $\mathrm{SEB}$ & $\beta$ & $\mathrm{t}$ & $\mathrm{p}$ & Zero-order $\mathrm{r}^{\mathrm{c}} \mathrm{sr}^{2}$ \\
\hline DASS-21 & 0.011 & 0.053 & 0.020 & 0.193 & 0.850 & 0.261 & $<0.001$ \\
CCS-L & -0.070 & 0.064 & -0.117 & -1.208 & 0.261 & 0.278 & 0.009 \\
CCS-S & 0.198 & 0.065 & 0.370 & 3.480 & 0.001 & 0.465 & 0.087 \\
DS-R & 3.250 & 1.743 & 0.174 & 1.885 & 0.050 & 0.371 & 0.028 \\
BVS & 0.278 & 0.157 & 0.189 & 1.871 & 0.061 & 0.356 & 0.024 \\
ASI-3 physical & 0.507 & 0.277 & 0.178 & 1.806 & 0.070 & 0.412 & 0.026 \\
EFQ & 0.487 & 0.627 & 0.057 & 0.807 & 0.432 & 0.051 & 0.005 \\
\hline
\end{tabular}

CFI: COVID-19 Fear Inventory, CCSB: COVID-19 Checklist for Safety Behaviors, DASS-21: Depression Anxiety Stress Scales-21, CCS-L: Contamination Cognitions Scale-Likelihood average, CCS-S: Contamination Cognitions Scale-Severity average, DS-R: Disgust Scale-Revised average, BVS: Body Vigilance Scale, ASI-3 Physical: Anxiety Sensitivity Inventory-3 Physical Concerns Subscale, CFQ: COVID-19 Fast Quiz, $\mathrm{sr}^{2}$ squared semi-partial correlation 
significant relationship of factual knowledge of COVID-19 and fear and engagement in safety behaviors of COVID-19. However, the findings go consistent with the previous research of Moritz and Pohl, ${ }^{45,46}$ where illness-related information like statistics of incidence did not show a significant relationship with anxiety-related symptoms. Our COVID-19 information quiz was taken from an online reliable source for which the psychometric properties were unknown, but the score distribution in our data was without skew or kurtosis and showed normality. COVID-19 is an ongoing pandemic in the world and has been declared as a public health emergency on international level. ${ }^{5}$ Yet as the National Institute of Health, Islamic Republic of Pakistan, declared it to be a catastrophe in Pakistan, the federal government imposed several restrictions throughout the country which include the closing of outpatient departments in the hospitals, bans on the intra and intercity public transports as well as the gatherings in public or private places, which rose the concern and fear among the general population and made COVID-19 fear a greater threat than the COVID-19 itself. ${ }^{47,48}$

The results suggest that the efforts to increase the knowledge of the COVID-19 outbreak might not alleviate the COVID-19 related fear and safety behaviors. This understanding brings some clinical relevance in a way that cognitive models highlighting dysfunctional beliefs like threat overestimation are of great importance as etiological factors for pathological anxiety which needs to be targeted in the individualized management plans. ${ }^{49}$ As an alternative explanation, it can be said that respondents coped with the fear of COVID-19 by seeking the required knowledge and the hypothesized effect was washed out. Consequently, the results of our research might seed cognitive interventions by stating that educating an anxiety patient about the epidemic alone, cannot become a strong method against dysfunctional health-related beliefs. As the research considered a non-clinical population, a future recommendation would be to consider a clinical population with health anxiety of clinical severity to see if providing knowledge about the epidemic could mitigate the fear and anxiousness among people.

To date, researchers have rarely focused on anxious responses to a threat of viral illnesses such as the COVID-19 outbreak in Pakistan. Given the fact that the country has been exposed to the virus and we were well-positioned to identify the predictors of fear and safety behaviors among young adults who are continuously getting information from media coverage about the outbreak in Pakistan. The purpose of this research was to enlighten the clinical practitioners and the psychologists who are continuously dealing with referrals for panic and anxiety symptoms regarding COVID-19. The research further highlights the behavioral responses of the public towards a threat of a pandemic and especially those people who are already vulnerable towards maladaptive responses such as health anxiety. Should a threat of another global panic surface in the future, this research could also help in developing preventative programs and the clinical management systems. The results of the research highlight that the contamination concern and the physical concerns about anxiety sensitivity might be essential in this experience of COVID-19 fear and related safety behaviors such as compulsive hand washing. However, COVID-19 related anxiety and behaviors were not found to be related to the factual understanding of this pandemic.

Along with other psychological determinants, anxiety sensitivity in the physical domain is a significant predictor of COVID-19 fear and safety behaviors. Findings of this research are cross-sectional, one of the ways through which anxiety sensitivity contributes to fearful responses against COVID-19 is by the possible misunderstanding of benign or universal bodily sensations as something threatening. Such a misunderstanding could lead to increased fear because the number of bodily sensations that are associated with anxiety often mirror the symptoms of COVID-19 (such as nausea). ${ }^{45}$ As previously hypothesized by the researcher, concerns the severity of contamination predict COVID-19 fear and safety behaviors. COVID-19 is indeed an illness with its severity in unpleasant symptoms like myalgia (muscle pain), cough, fever, or fatigue ${ }^{45}$ but it is also a possibility that increased media coverage led people to overestimate the severity of this disease. A similar pattern was discussed in research with undergraduate students by Wheaton et al. ${ }^{9}$ They studied the fearful responses of youngsters towards H1N1 pandemic known to existed from 2009 to 2010. Though, findings of present research can't suggest a causal relationship of increased media coverage and fear of COVID-19 and safety behaviors.

The design of this research was inspired by Wheaton et al., ${ }^{9}$ where anxious responses against H1N1 were explored after the 2009 outbreak. The authors suggested that likelihood and severity in contamination cognition, health anxiety, and disgust sensitivity significantly predicted fear of H1N1. However, it was reported that physical concerns regarding anxiety sensitivity, general distress, and body vigilance were not connected to fear of illness (H1N1). Therefore, it can be stated that our result is somewhat consistent with the previous research of Wheaton and colleagues. It is recommended for future researches that a comparison study should be conducted to see the amount of perceived dangerousness, disgusting, and controllability for certain outbreaks.

Some of the limitations of this research should be considered while citing this research in the future. Firstly, the participants were undergraduate students from Pakistan, and they were physically and psychologically healthy. Therefore, the 
findings cannot be applied to individuals with clinical symptoms like OCD or hypochondriasis. Secondly, participants were recruited from undergraduate university students from Pakistan and the results cannot be implicated to all the youngsters from Pakistan with otherwise similar demographic properties because people experience a differentiated level of concerns according to the level of incidence in that region. It would be desirable if similar research with global representation can be conducted in the future. Another limitation would be, that data was based on subjective representations which could inflate the associations of variables.

At last, the research provides directional conclusions. It is suggested that people with a greater concern of contamination are likely to respond to fearfully to COVID-19 and that people with higher fear of COVID-19 are likely to feel contamination concerns. In the future, longitudinal research would be of great benefit in determining the predictability of constructs towards health anxiety as a response to global epidemics or the threat of serious diseases. Likewise, the chances that safety behaviors could generate or increase COVID-19 concerns are important in the light of the study suggesting that intentional engagement in health-related safety activities makes individuals more concerned about the risk of contamination..$^{50}$ The present research provides data in relevance to understanding psychological pointers for anxious responding to global epidemics.

\section{Acknowledgments}

\section{None.}

\section{Conflicts of Interest}

The authors have no potential conflicts of interest to disclose.

\section{Author Contributions}

Conceptualization: Li Hongbo. Data curation: Alishba Hania, Muhammad Waqas. Formal analysis: Muhammad Waqas, Li Hongbo. Investigation: Alishba Hania, Muhammad Waqas. Methodology: Li Hongbo, Alishba Hania. Project administration: Alishba Hania. Resources: Muhammad Waqas. Visualization: Muhammad Waqas, Alishba Hania. Writing-original draft: Alishba Hania, Li Hongbo. Writing_-review \& editing: Muhammad Waqas.

\section{ORCID iD}

Muhammad Waqas

Alishba Hania

Li Hongbo https://orcid.org/0000-0003-4098-5994

https://orcid.org/0000-0003-4617-6784

https://orcid.org/0000-0003-3825-675X

\section{REFERENCES}

1. World Health Organization (WHO). Coronavirus disease (COVID-19) outbreak webpage Available at: https://experience.arcgis.com/experien ce/685d0ace521648f8a5beeeee1b9125cd. Accessed March 15, 2020.

2. Taylor S, Asmundson GJ. Treating Health Anxiety: A Cognitive-Behavioral Approach. New York: Guilford Press; 2004.

3. Huang C, Wang Y, Li X, Ren L, Zhao J, Hu Y, et al. Clinical features of patients infected with 2019 novel coronavirus in Wuhan, China. Lancet 2020;395:497-506.

4. Chen N, Zhou M, Dong X, Qu J, Gong F, Han Y, et al. Epidemiological and clinical characteristics of 99 cases of 2019 novel coronavirus pneumonia in Wuhan, China: a descriptive study. Lancet 2020;395:507-513.

5. Lu R, Zhao X, Li J, Niu P, Yang B, Wu H, et al. Genomic characterization and epidemiology of 2019 novel coronavirus: implications for virus origins and receptor binding. Lancet 2020;395:565-574.

6. Rubin GJ, Wessely S. The psychological effects of quarantining a city. BMJ 2020;368;m313.

7. Blakey SM, Jacoby RJ, Reuman L, Abramowitz JS. The relative contributions of experiential avoidance and distress tolerance to OC symptoms. Behav Cogn Psychother 2016;44:460-471.

8. Lau JT, Kim JH, Tsui HY, Griffiths S. Perceptions related to bird-to-human avian influenza, influenza vaccination, and use of face mask. Infection 2008;36:434-443.

9. Wheaton MG, Abramowitz JS, Berman NC, Fabricant LE, Olatunji BO. Psychological predictors of anxiety in response to the H1N1 (swine flu) pandemic. Cogn Ther Res 2012;36:210-218.

10. Wong TW, Gao Y, Tam WW. Anxiety among university students during the SARS epidemic in Hong Kong. Stress Health 2007;23:31-35.

11. Abramowitz JS, Braddock AE. Hypochondriasis and Health Anxiety. Cambridge, MA: Hogrefe Publishing; 2011.

12. Abramowitz JS, Moore EL. An experimental analysis of hypochondriasis. Behav Res Ther 2007;45:413-424.

13. Helbig-Lang S, Petermann F. Tolerate or eliminate? A systematic review on the effects of safety behavior across anxiety disorders. Clin Psychol 2010;17:218-233.

14. American Psychological Association. Specialty Guidelines for Forensic Psychology. Am Psychol 2013;68:7.

15. Pellino G, Spinelli A. How COVID-19 outbreak is impacting colorectal cancer patients in Italy: a long shadow beyond infection. Dis Colon Rectum 2020 [Epub ahead of print].

16. World Health Organization. Middle East respiratory syndrome coronavirus (MERS-CoV). Available at: https://www.who.int/emergencies/ mers-cov/en. Accessed March 17, 2020.

17. Gazzetta Ufficiale della Repubblica Italiana GU Serie Generale n 64 del 11/03/2020 Available at: https://www.gazzettaufficiale.it/atto/serie_ generale/caricaDettaglio At to/originario? at to. dataPubblicazioneGazzetta $=2020-03-11$ \&atto.codiceRedazionale $=20$ A01605\&elenco30giorni=false. Accessed March 14, 2020.

18. Spinelli A, Pellino G. COVID-19 pandemic: perspectives on an unfolding crisis. Br J Surg 2020;107:785-787.

19. Centers for Disease Control and Prevention. Frequently asked questions about SARS. 2005. Available at: https://www.cdc.gov/sars/about/ faq.html. Accessed March 17, 2020.

20. Mowbray H. In Beijing, coronavirus 2019-nCoV has created a siege mentality. BMJ 2020;368:m516.

21. Gigerenzer G. Risk Savvy: How to Make Good Decisions. London: Penguin; 2015.

22. Mukhtar F, Mukhtar N. Coronavirus (COVID-19): Let's prevent not panic. J Ayub Med Coll Abbottabad 2020;32:141-144.

23. Bish A, Michie S. Demographic and attitudinal determinants of protective behaviours during a pandemic: a review. Br J Health Psychol 2010;15:797-824.

24. Olatunji BO, Sawchuk CN. Disgust: characteristic features, social manifestations, and clinical implications. J Soc Clin Psychol 2005;24: 932-962.

25. Scott KM, Bruffaerts R, Tsang A, Ormel J, Alonso J, Angermeyer MC, et al. Depression?anxiety relationships with chronic physical conditions: results from the World Mental Health Surveys. J Affect Disord 2007;103:113-120.

26. Niles AN, Dour HJ, Stanton AL, Roy-Byrne PP, Stein MB, Sullivan G, et al. Anxiety and depressive symptoms and medical illness among adults with anxiety disorders. J Psychosom Res 2015;78:109-115.

27. Rief W, Hiller W, Margraf J. Cognitive aspects of hypochondriasis and the somatization syndrome. J Abnorm Psychol 1998;107:587-595.

28. Cisler JM, Brady RE, Olatunji BO, Lohr JM. Disgust and obsessive be- 
liefs in contamination-related OCD. Cognit Ther Res 2010;34:439-448.

29. Olatunji BO, Williams NL, Tolin DF, Abramowitz JS, Sawchuk CN, Lohr JM, et al. The Disgust Scale: item analysis, factor structure, and suggestions for refinement. Psychol Assess 2007;19:281-297.

30. Schmidt NB, Lerew DR, Trakowski JH. Body vigilance in panic disorder: evaluating attention to bodily perturbations. J Consult Clin Psychol 1997;65:214-220.

31. Olatunji BO, Deacon BJ, Abramowitz JS, Valentiner DP. Body vigilance in nonclinical and anxiety disorder samples: structure, correlates, and prediction of health concerns. Behav Ther 2007;38:392-401.

32. Taylor S, Zvolensky MJ, Cox BJ, Deacon B, Heimberg RG, Ledley DR, et al. Robust dimensions of anxiety sensitivity: development and initial validation of the Anxiety Sensitivity Index-3. Psychol Assess 2007;19: 176-188.

33. American Psychological Association. Managing your fear about Ebola. 2014. Available at: http://www.apa.org/helpcenter/ebola-fear.aspx. Accessed April 4, 2020.

34. Meade AW, Craig SB. Identifying careless responses in survey data. Psychol Methods 2012;17:437-455.

35. Antony MM, Bieling PJ, Cox BJ, Enns MW, Swinson RP. Psychometric properties of the 42-item and 21-item versions of the Depression Anxiety Stress Scales in clinical groups and a community sample. Psychol Assess 1998;10:176-181.

36. Lovibond S, Lovibond P. Manual for the Depression Anxiety Stress Scales (2nd Edition. Sydney: Psychology Foundation; 2005.

37. Henry JD, Crawford JR. The short-form version of the Depression Anxiety Stress Scales (DASS-21): Construct validity and normative data in a large non-clinical sample. Br J Clin Psychol 2005;44:227-239.

38. Deacon B, Maack DJ. The effects of safety behaviors on the fear of contamination: an experimental investigation. Behav Res Ther 2008;46: 537-547.
39. Haidt J, McCauley C, Rozin P. Individual differences in sensitivity to disgust: a scale sampling seven domains of disgust elicitors. Pers Individ diff1994;16:701-713.

40. Schmidt NB, Lerew DR, Trakowski JH. Body vigilance in panic disorder: evaluating attention to bodily perturbations. J Consult Clin Psychol 1997;65:214-220.

41. Reise SP, Morizot J, Hays RD. The role of the bifactor model in resolving dimensionality issues in health outcomes measures. Qual Life Res 2007;16:19-31.

42. Covid-19 Fast Quiz. Uk's Independent Fact Checking Authority. Available at https:// fullfact. Org / quiz / coronavirus/. Accessed March 1, 2020

43. DeVellis RF: Scale Development: Theory and Applications (Vol 26). Newbury Park, CA: Sage Publications, Inc; 2003.

44. Nunnally JC, Bernstein IH. Validity. Psychom Theory 1994;3:99-132.

45. Zu ZY, Jiang MD, Xu PP, Chen W, Ni QQ, Lu GM, et al. Coronavirus disease 2019 (COVID-19): a perspective from China. Radiology 2020; 296:E15-E25.

46. Moritz S, Pohl RF. Biased processing of threat-related information rather than knowledge deficits contributes to overestimation of threat in obsessive-compulsive disorder. Behav Modif 2009;33:763-777.

47. COVID-19 Daily Situation Report-NIH Pakistan" (PDF). Available at: www.nih.org.pk/. 16 March 2020. Accessed March 20, 2020.

48. COVID-19: Pakistani hospitals suspend outpatient clinics." Anadolu Agency. 25 March 2020. Accessed March 25, 2020.

49. Fergus TA. Health-related dysfunctional beliefs and health anxiety: further evidence of cognitive specificity. J Clin Psychol 2014;70:248-259.

50. Olatunji BO, Etzel EN, Tomarken AJ, Ciesielski BG, Deacon B. The effects of safety behaviors on health anxiety: an experimental investigation. Behav Res Ther 2011;49:719-728. 